\title{
Virtualizing Project-Based Learning: An Abrupt Adaptation of Active Learning in the First Days of the COVID-19 Pandemic, with Promising Outcomes
}

\author{
Marco Antonio Carvalho Pereira ${ }^{1, *}$, Luísa Miranda Nunes da Costa Ignácio ${ }^{1}$ and Cristiano E. Rodrigues Reis ${ }^{2} \mathbb{D}$ \\ 1 Engineering School of Lorena, University of São Paulo, Lorena 12602-810, SP, Brazil; luisaignacio.c@usp.br \\ 2 EARTH University, Las Mercedes, Guacimo P.O. Box 4442-1000, Limon, Costa Rica; crodrigues@earth.ac.cr \\ * Correspondence: marcopereira@usp.br
}

Citation: Pereira, M.A.C.; Ignácio, L.M.N.d.C.; Rodrigues Reis, C.E. Virtualizing Project-Based Learning: An Abrupt Adaptation of Active Learning in the First Days of the COVID-19 Pandemic, with Promising Outcomes. Sustainability 2022, 14, 363 https://doi.org/10.3390/su14010363

Academic Editor: Changhyun Roh

Received: 26 October 2021

Accepted: 20 December 2021

Published: 30 December 2021

Publisher's Note: MDPI stays neutral with regard to jurisdictional claims in published maps and institutional affiliations.

Copyright: (C) 2021 by the authors. Licensee MDPI, Basel, Switzerland. This article is an open access article distributed under the terms and conditions of the Creative Commons Attribution (CC BY) license (https:// creativecommons.org/licenses/by/ $4.0 /)$.

\begin{abstract}
Project-based learning (PBL) is renowned as an active learning practice that promotes the application of the accumulation of knowledge through real-world and often open-ended problems. This work assesses a case evaluation of an introductory PBL course in a typical industrial engineering curriculum in Brazil. This course is taken during the first semester, in which students must develop solutions for a single given problem through weekly meetings. The case presented herein highlights the forced abrupt virtualization of the learning process, which imposed an unprecedented scenario on the students and instructors, especially with regard to this course, which is based primarily on presented discussions and activities. The first weeks of class following the abrupt virtualization of activities encountered misinformation and a lack of clarity about the adaptation of the activities. Fortunately, through rapid iterations, the adjustment process resulted in time invested by the students and classes, with an active discussion, using the tools made available by the university. This work aims to present the forced abrupt changes applied to this first-semester course, highlighting the challenges faced, and the positive outcomes obtained and observed by both the students and the instructor, and to make a comparison to the evolution of the course over the past years.
\end{abstract}

Keywords: COVID-19; project-based learning (PBL); engineering education; virtualization

\section{Introduction}

The challenges involved in recreating novel and adaptable strategies in training future generations of engineers often converge along pathways leading to the roles of each participant in the classroom. The long-standing tradition of passive-oriented courses, with a unidirectional flow of knowledge coming from the active agent in the classroom, i.e., the instructor, reaching the learners, who stand as passive receptors of information, is often regarded as a method that fails to meet the majority of the objectives related to the learning process [1]. Among the strategies for overcoming the obstacles to which traditional engineering education is set, some active learning strategies have been developed over the past decades, with the main goal of transferring the flow of information within a classroom setting [2]. These methodologies address the students as the main characters, i.e., as the active agents of the learning process, making them responsible for gathering and working on the process of accumulating knowledge.

The use of project-based learning (PBL), as a practice to promote active learning experiences, was built upon a wide array of successful cases based on real-world and challenging situations, for both the students and the instructors. Since 2013, the Engineering School of Lorena, at the University of São Paulo, Brazil, has been offering courses with teaching and learning practices primarily based on PBL [3]. The career in industrial engineering at the aforementioned institution has three mandatory courses, which students must take in the first, fourth, and seventh semesters of their twelve-semester program. The courses are entirely based on PBL and they aim to promote learning through the 
development and prototyping of solutions for complex problems through weekly class meetings. The evolution of the activities, coupled with the lessons learned over this eight-year frame, have led to some early conclusions about the learning of techniques and concepts that are directly related to the main technical competencies one would expect from a successful industrial engineer, in consonance with what has been observed in schools in different parts of the world, such as in South Africa, Morocco [4], Portugal [5], Denmark, and China [6]. Furthermore, our findings also demonstrate that the application of PBL in these courses served as a strong catalyst for the enhancement of transversal competencies in the students, which are often disregarded, or are at least not directly evaluated in the traditional and passive-learning classroom experience.

These mandatory PBL courses make up the Integrated Project in Industrial Engineering (IPIE), and they are divided according to the technical complexity of the industrial engineering tools one would expect from a student at a given point in their curriculum. The first IPIE course, offered to first-semester students, is offered as an introduction to the methodology, and its problem scope, over the last years, has been based on the Sustainable Development Goals (SDG) for the year 2030, set by the United Nations. The projects developed by the first-semester students are, thus, often not strictly related to complex industrial engineering practices, but, rather, also to the diverse settings that a typical freshman student can encounter, building up from previous experiences. Over the past years, a portfolio of IPIE projects has been developed, aimed at promoting solutions to the matrices of renewable energy, engaging youth in STEM (Science, Technology, Engineering, and Mathematics) practices, and, more recently, in 2020, promoting solutions for the challenges of providing accessible and effective education to children in their school years in Brazil.

The calendar of academic activities in Brazil typically starts in late February and runs for 15 weeks. In a matter of a few weeks of classes in 2020, the COVID-19 pandemic forced an abrupt virtualization of the learning process, imposing an unprecedented scenario upon the students and the instructors, especially with regard to this course, which is based primarily on presented discussions and activities, which were not able to be moved to a virtual setting, or so it was previously thought. Fortunately, the adaptation of the classroom activities promoted results that demonstrated that more time was invested by the students and classes, with an active discussion using the tools made available by the university. This article aims to demonstrate the abrupt forced changes applied to the PBL-intensive IPIE at the Engineering School of Lorena, illustrating the challenges faced, and the positive outcomes obtained and observed by both the students and the instructor, and to make a comparison to the evolution of the course over the past years. It is hoped that our findings, while still in the shadow of the uncertainties caused by the pandemic, will demonstrate some of the lessons learned for the years to come, as well as the adaptation of online spaces of learning applied to courses that were not traditionally designed to be virtualized. We hope that the findings and the challenges yield valuable references for future learners and teachers in the post-COVID-19 era in engineering education.

\section{Scope and Research Methodology}

The research method applied was the case study analysis. This qualitative method has an induction approach to the analysis of data, and focuses on the description of the results and their meaning [7]. The case study approach is an empirical approach, as this method approaches the investigation of a real phenomenon within the context of the real world, often considering that the boundaries between the phenomenon and the context are not clearly defined.

\subsection{Structure, Scope, and Milestones of IPIE 1}

IPIE 1 is taught for first-semester students enrolled in the industrial engineering program at the Engineering School of Lorena. Its structure is based on a 15-week semester, with weekly meetings of 100 minutes each. The coursework from previous years, i.e., from 2013 until 2019, was entirely based on face-to-face meetings, while just the first two classes 
followed the in-person-based structure. The structure of the first class was divided into segments, dedicated to the introduction of the course and the division of the students into teams. Students were classified according to their academic experience, i.e., the students that had already been enrolled in other higher education courses, regardless of the subject, were grouped separately from those that had never been part of any higher education activity, reaching a balance of two groups within the first classification, and six groups within the latter. The first class was also useful in that the students became acquainted with their groups, and were able to initially familiarize themselves with the theme of the projects for the semester session, which was based on the fourth Sustainable Development Goal: Quality Education. The instructor introduced the need to develop solutions to the problems facing the educational needs of Brazil, and later introduced the syllabus and the expected deliveries from the students during the coursework. The first of these was the concept of the project each group would be working on, which was presented in the second week of classes. Each presentation lasted for approximately five minutes, which was followed by feedback from the instructor. The third week of classes, following what was planned on the syllabus, did not occur, as it coincided with the declaration that COVID-19 had become a pandemic situation, which resulted in an immediate response from the university to shut down all in-person programs.

The virtualization began with an adjustment to the program in the fourth week of classes, using the Google Meet platform. The third class revolved around the theme of project management, which was introduced through Project Model Canvas by the instructor. The thirty-minute theoretical and practical exposition was followed by private meetings, with each group using the virtual room setting of the learning platform. The following week was based on a similar structure but was focused on the development of a research project. The expectations of the instructor were for the students to deliver a research project in the fifth class. The fifth class had, as an introductory framework, the importance of teamwork, and was conducted by an external guest. The students were expected to deliver some tasks aimed at a better understanding of teamwork and the relevance of this skill to project development. The sixth and seventh classes were dedicated to designing thinking, and were also hosted by a guest, while the eighth class focused on oral and written communication skills. The eighth class was also the deadline for which the students had to deliver their preliminary reports, in which they had to describe the prototype of what they were building in their projects. This was followed by the delivery of the prototype in the ninth class, through a five-minute presentation, which was examined by four professors, who were invited to serve as evaluators in this class.

The tenth and eleventh classes were aimed at introducing the students to the norms of scientific writing. In the twelfth class, six students, who were in their last year of studies, gave a short presentation, allowing a roundtable discussion to take place with regard to some of the expectations of the first-year students. The thirteenth and fourteenth classes were based on meetings and feedback from the instructor, aimed at solving point issues in the projects that were supposed to be presented in the fifteenth class. The last week of classes was hosted by the instructor, with six professors serving as the evaluators of each project.

\subsection{Data Collection}

The data collection for the study was conducted via a questionnaire analysis in the last week of classes, through an analysis of the work reports, and through the point observations of the instructor, as well as other stakeholders that were not members of the student groups working on the projects. The data collected from the plethora of evidence and the multiple focal points allowed us to use the triangulation technique, which consists of an analysis between the different data points [8]. The triangulation of the data allows for the visualization of possible converging and diverging points, and opens the possibility of integrating quantitative points to qualitative data, and vice versa, according to Flick [9]. 
The questionnaire contained a total of 28 questions, the answers to which were based on a 5-point Likert scale: 1 (strongly disagree); 2 (partially disagree); 3 (neither disagree nor agree); 4 (partially agree); and 5 (totally agree), followed by an open-ended question aimed at collecting general feedback for the course. Each questionnaire was answered individually. The questionnaire used in the study is presented as Table 1.

Table 1. The questionnaire used in the last class of the IPIE 1 course in 2020.

\begin{tabular}{|c|c|c|}
\hline Category & Question ID & Assertive \\
\hline \multirow{3}{*}{ PBL } & 1 & \multirow{3}{*}{$\begin{array}{c}\text { The use of PBL was a differential to IPIE1. } \\
\text { PBL concepts should be applied in other courses of my career. } \\
\text { The use of PBL methodology made my learning more } \\
\text { motivating. }\end{array}$} \\
\hline & 2 & \\
\hline & 3 & \\
\hline \multirow{12}{*}{ Teamwork } & 4 & $\begin{array}{l}\text { The team was able to properly assess the different points of } \\
\text { view about the project. }\end{array}$ \\
\hline & 5 & The team was agile in making decisions. \\
\hline & 6 & $\begin{array}{c}\text { My team researched the project's theme using the most varied } \\
\text { sources. }\end{array}$ \\
\hline & 7 & $\begin{array}{l}\text { The role of each member of the team was well-defined, and } \\
\text { everyone worked in their proper roles. }\end{array}$ \\
\hline & 8 & $\begin{array}{c}\text { My team knew how to manage time well and fulfilled the } \\
\text { proposed schedule. }\end{array}$ \\
\hline & & Everyone on my team was very understanding about the \\
\hline & 9 & different ideas that came up in the execution of the project. \\
\hline & 10 & $\begin{array}{l}\text { All members of my team have shown themselves to be } \\
\text { responsible for carrying out all the tasks assigned to them. }\end{array}$ \\
\hline & 11 & $\begin{array}{l}\text { My team's success was a function of the cooperation of all its } \\
\text { members. }\end{array}$ \\
\hline & 12 & $\begin{array}{l}\text { The execution of the project improved the development of the } \\
\text { interpersonal relationships of everyone on the team. }\end{array}$ \\
\hline & 13 & $\begin{array}{l}\text { All conflicts experienced by the group were overcome in a } \\
\text { coherent and respectful manner. }\end{array}$ \\
\hline & 14 & I realize that I learned to seek innovative solutions. \\
\hline \multirow{6}{*}{$\begin{array}{c}\text { Personal } \\
\text { Development }\end{array}$} & 15 & $\begin{array}{l}\text { I had the initiative to collaborate with the team, even when I } \\
\text { was not asked to do so by the leader. }\end{array}$ \\
\hline & 16 & $\begin{array}{l}\text { I realize that I have a greater critical sense that helps me to } \\
\text { evaluate the different work proposals. }\end{array}$ \\
\hline & 17 & I adapted easily to unexpected situations that arose during \\
\hline & 17 & the execution of the project. \\
\hline & 18 & My view on ethics has been improved in this project. \\
\hline & 19 & $\begin{array}{l}\text { The decisions that were made considered the impact of the } \\
\text { project on the people involved. }\end{array}$ \\
\hline \multirow{3}{*}{ Communication } & 20 & $\begin{array}{l}\text { The group communication using the assigned protocol was } \\
\text { effective. }\end{array}$ \\
\hline & 21 & My written communication evolved because of the project. \\
\hline & 22 & My oral communication evolved because of the project. \\
\hline \multirow{5}{*}{$\begin{array}{l}\text { Integration with } \\
\text { other courses }\end{array}$} & 23 & $\begin{array}{l}\text { I was able to verify a relationship between Calculus I and } \\
\text { what I worked on in the project. }\end{array}$ \\
\hline & & I was able to verify a relationship between General Chemistry \\
\hline & 24 & $\begin{array}{l}\text { I and General Experimental Chemistry I and what I worked } \\
\text { on in the project. }\end{array}$ \\
\hline & & I was able to verify a relationship between Reading and \\
\hline & 25 & $\begin{array}{l}\text { Interpreting the Portuguese Language and what I worked on } \\
\text { in the project. }\end{array}$ \\
\hline \multirow{3}{*}{$\begin{array}{l}\text { Leadership and } \\
\text { Tutor presence }\end{array}$} & 26 & The Tutor participated whenever called by the group. \\
\hline & 27 & The contributions made by the Tutor were relevant. \\
\hline & 28 & The leader knew how to lead the team very well. \\
\hline
\end{tabular}




\section{Results}

The quantitative results were obtained following the assessment of the questionnaire at the end of the first semester of 2020, are they are summarized in Figure 1. From a visual analysis, it can be observed that the overall majority of the results ranged from 4 to 5 on the Likert scale, i.e., between "partially agree" and "totally agree".

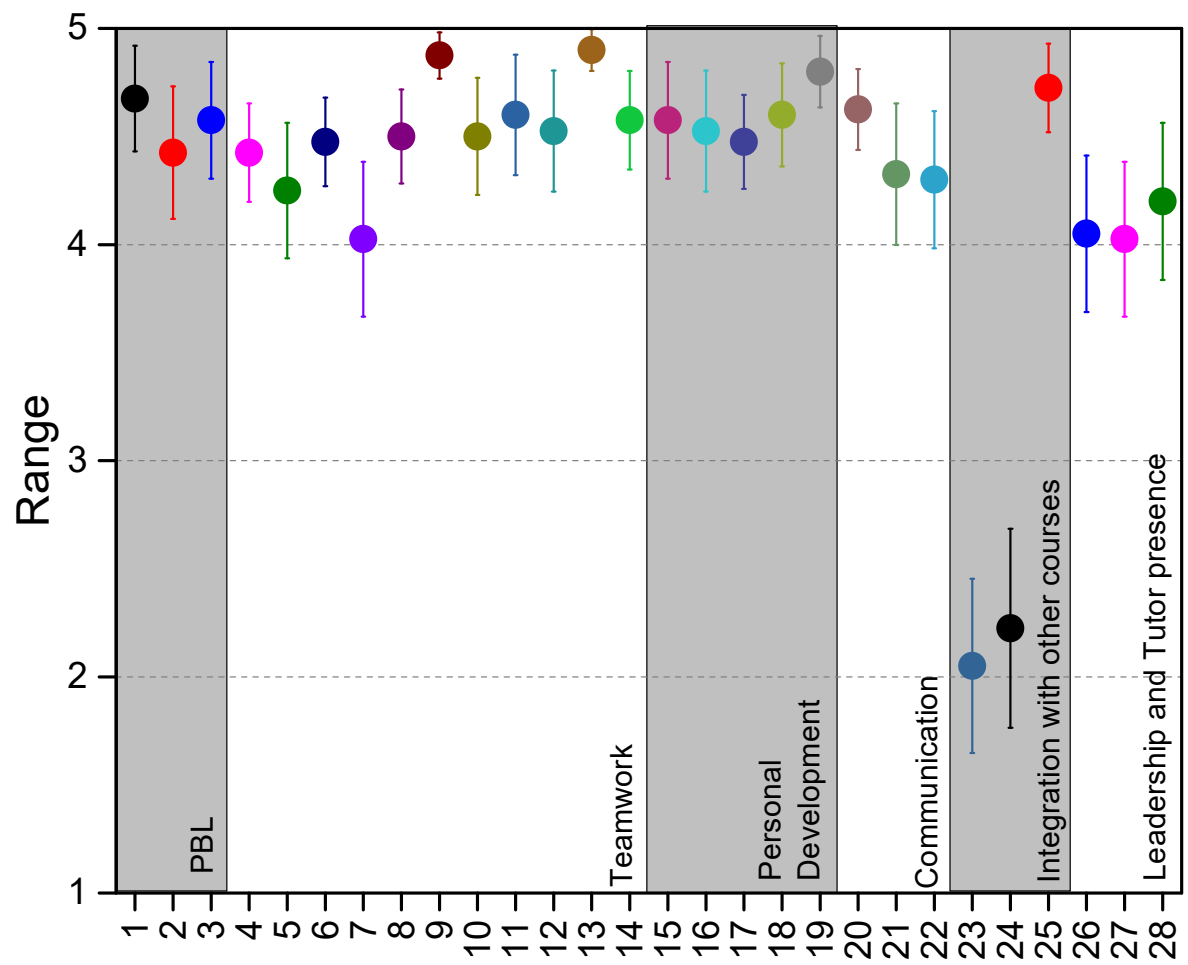

\section{Assertive}

Figure 1. Scores of the responses and the ranges of their 95\% confidence level on a 5-point Likert scale $(n=40)$.

The responses of the students with regard to the acceptance of the PBL model are totally within the range of "partially agree" to "totally agree", demonstrating not only that the methodology was differential to the course and that it made their coursework more interesting, but also that they believe that PBL should be applied to other courses in their academic career. Thus, these results validate the recognition by the students of the importance of PBL to their professional training.

Our assessment also encompassed an evaluation of the perceptions of the students with regard to their responses towards two transversal competencies: teamwork and personal development, and technical competence and project management. An analysis of these responses revealed that the students had an overall good reception towards these values, as the majority were between the 4 and 5 range. The two data points with the lowest scores were found in Question 7, regarding the division of roles and the individual contribution to the overall success of the group project. This question, in particular, possibly demonstrated some level of frustration from some team members that likely felt their work was unbalanced towards the average contribution to the objectives of the project. It is interesting to highlight the maturity of the students, especially taking into account that most of them have never been enrolled in a higher education program before enrolling in this course. The questions related to personal development were, again, all valued within the 4 to 5 range, demonstrating that the students felt that the methodology and the course project assisted them in building capacities related to creativity, critical sense, and ethics.

Two of the categories that should be carefully inspected herein are leadership, and the integration of the concepts learned in IPIE 1 and other courses from their academic career, 
as these had lower scores in the evaluation. Regarding the leadership presence in the group, and the role of a tutor in the group activities, while the average score was within the 4 to 5 range, the confidence level of the range led to perceptions within the "neither agree nor disagree" field. Some feedback given by the students in the open feedback question was that one "believes that a greater contact between the team and tutor would be beneficial to verify how the support is being given, and vice versa" and that there should have "more significant tutor presence in the activities". The points related to the integration with other courses were the lowest scores overall of the questionnaire, demonstrating that the students felt that the activities in the course did not converge to the courses in General Chemistry and Calculus 1, which are taken simultaneously, while the course, Reading and Interpreting the Portuguese Language, was scored higher. It is important to highlight that the objectives of the latter course were designed to give students the technical skills required to read, interpret, and produce technical texts in an academic setting.

\section{Discussion within the Context of the Abrupt Virtualization}

The forced and abrupt adaptation to a virtual setting for the course was implemented after two weeks of activities. The students, the tutors, and the instructor all reached an agreement that, until further notice, the activities would consist of a mixture of synchronous and asynchronous teaching and working modes. It is noteworthy that, given the circumstances, only seven of the forty open-ended responses mentioned anything related to the virtualization or the effects of the COVID-19 pandemic on the course. Some of these comments included:

1. "I believe that my experience in this course was complete. There were some limitations regarding virtual learning, nonetheless, the alternatives in which the course work was managed were valid and they led to a full learning experience and the possibility of the project execution";

2. "The transfer from the face-to-face to the virtual setting was well executed, and did not lead to significative losses concerning PBL";

3. "Even with the setbacks related to the pandemics, I believe the course was well planned and taught".

While there was not any question in the questionnaire evaluating the perceptions of the students towards the adaptation to virtualization, it can be assumed that, while the process was forced abruptly, their responses to the virtual meetings and the adapted teaching mode were, overall, positive. We did not identify any negative feedback that was directly related to the adaptation process, and, within a greater context, the instructor and the external stakeholders of the class felt that the students were as engaged, or slightly more engaged, when compared to previous years of the course. Our main assumption to this fact would be that this PBL course was among the few that allowed and encouraged students to actively participate in group discussions. Student engagement has been reported as a core advantage that has been measured as an outcome of different PBL approaches in engineering education [10-12].

We also relate to the evidence of the proactivity of some students with regard to the submission of the final product as a conference paper, of which all were encouraged to be a part of, even though it was not a mandatory part of the grading for the course. The students were encouraged to prepare a submission to, and to participate in, the COBENGE (Congresso Brasileiro de Educação em Engenharia, freely translated as the Brazilian Congress in Engineering Education), taking into consideration that their outcomes were directly related to the implementation or development of technologies, products, or processes in the context of the SDG of Quality Education. We highlight two of these papers herein, which were published at the proceedings of the 48th COBENGE: (i) "Youtube Channel forwarding Quality Education in Brazil" [13]; and (ii) "Educational Strategies and their Different Applications as a Complement in promoting Equitable Education" [14]. Both papers were presented at a national-level conference, with a focus on engineering education and on promoting the early entrance of undergraduate students to platforms dedicated to 
the promotion of science speaking and discussion. The literature is diffuse in terms of evaluating the motivations of students in participating in events as an outcome for outstanding projects, but Nikita et al. [15] highlight that such active research work can foster an interest in scientific research, and can also pose advantages in a potential postgraduate career.

The scope of the classes was to be set according to virtual meeting platforms. Serhan [16] demonstrated that the use of video conferencing classes allowed the students to have more flexibility, and that it led to easier interaction, better written communication, and the effective use of multimedia. The same author, on the other hand, cites that the main advantages he found in the survey were also related to distractions, to the quality of the interaction and feedback, to technical difficulties, and to poorer education quality. Within our observations, the students were excited to participate in the virtual classroom, and the experience led, overall, to projects that were perceived by the instructor and the guest evaluators to be deeper and more complex when compared to those of previous years. We were not able to distinguish the points related to poorer educational quality highlighted by Serhan [16], given the considerations of this study. The feedback we received had some responses that are related to those reported by Gelles et al. [17], which, in this case, overlapped with the perceptions of the students and their reception to the use of PBL, such as:

4. "The classes were excellent. The use of PBL went beyond the expectations of what one learns in the course. I improved my proactivity, my communication, my teamwork, and overall, this course capacitated me as a professional and as a person. ( . . ) I wish all the courses were like this";

5. "This (virtual learning) experience was unexpected and good for me, considering the pandemic situation. I had the chance to develop some of my abilities, to work in a team, and to think outside the box. (The course) was challenging, but with a lot of learning."

Bao [18] identified five impactful principles for effective teaching practices in online settings. These principles are based on the appropriate balance between an online design and the student learning process, on effective delivery processes of the instructional information, on the adequate support and feedback of the instructors, on the effective and in-depth participation of the students in the learning process, and on a strong and iterative contingency plan to work around the unexpected incidents of online platforms. We believe that part of the promising results obtained in this case study can be related to most, if not all, of these principles. It should be highlighted that the objectives of, and the operational approaches to this course were not, and will likely not be, related to purely online platforms in the post-pandemic world.

To a larger extent, the replacement of face-to-face learning with virtual practices has been the basis of the emergency adaptation to the COVID-19 pandemic in many parts of the world, which has led to an important debate that is based on what will happen once we can effectively curb the sanitary crisis. While the move to the virtual setting has not been easy, there have been significant investments in overcoming technological barriers in order to support both students and faculty members. Our findings can be related to those of Affouneh et al. [19], who report on the adaptation to the rapid virtualization process at a university in Palestine. Affouneh et al. [19] observed that, even for those who are technological experts, there was a harsh adaptation process from face-to-face learning to online settings, and the difficulties of the instructors to the adaptation were not only about technological tools, but were also about the appropriate approaches for their effective application. The findings of this work demonstrate that PBL, given the appropriate conditions, could be adapted to virtual teaching and learning settings.

We relate this success to a few points, which are all linked to the context of this study. The first is related to the timescale of the group analysis, which was in the first weeks and months of the pandemic, when the uncertain and naïve perception was that the perduring effects of social distancing and the isolation mechanisms would be, at most, a few months long. This could have caused positive perceptions towards the adaptation mechanism on 
behalf of the students, as there was a feeling that they would likely soon be in a physical setting again. The second point concerns the size of the group. The student count was 40 students, which was still appropriate for effective communication and feedback. The structure in which the class was set up was transposable to a virtual setting in the sense that the communication among the students was possibly as effective when compared to the face-to-face design. The readiness and preparedness of the classroom participants, including the instructor and the students alike, was also a key factor, which did not level off the baseline of an effective learning process, as highlighted by the feedback comments: "the transfer to the virtual setting was easy and effective, and the process did not leave anything behind".

While we understand that the case reported herein was based in a setting with a lower incidence of technical issues than in many parts of the world, it is important to stress the points raised by Khlaif et al. [20], who highlight that student engagement in virtualized courses is impacted by infrastructure factors. There is the worrying issue of technological access and digital inequality in the learning community that, unsurprisingly, lead to unlikely success in the engagement of the learning community. In terms of virtualized learning, and when considering courses that require rapid and constant feedback, such as PBL-based courses, access to the Internet, devices, and technical support become an additional pillar of good quality education.

The outcomes of the reflections provided by the feedback of the students also resonate with the importance of student feedback to the educational evolution process. The feedback and the effective communication channel with the students provided the instructor with a clearer idea as to how to plan classes and meetings. The comments and engagement served as good indicators for the crisis management strategy adopted amidst the early chaos of the pandemic. In this sense, as reported by Rapanta et al. [21], the rapid adaptation to the virtual learning scenario, which fits with the case reported in this article, highlights the need for educational and pedagogical shifts towards flexible operational models that better reflect the complexity of the society we live in, given all its unpredictability and interconnectivity.

\section{Conclusions and Implications for Virtualized PBL Courses}

The findings described in this study represent a share of the personal perceptions collected during an early phase of the COVID-19 pandemic. The data collection and the subsequent analyses were carried out prior to the availability of COVID-19 vaccines, during the adaptation in the first term to virtualization. The abrupt adaptation to virtualization implied that a vast majority of activities, including university courses, had to be adapted to the circumstances that were available. The rapid adaptation, nonetheless, demonstrates that PBL, given the correct tools, can possibly be adapted to a virtual learning setting. The experience of virtualizing the IPIE amidst the early days of the COVID-19 pandemic provided a number of lessons learned for the wellbeing of the course and for PBL-like courses. According to our observations, some of the reasons are related not to the preparedness of the instructor or of the institution, but, rather, to effective communication, rapid feedback, and student encouragement.

Considering all these aspects, our findings are found at the incipient phase of possibly hybridized PBL classes in the future, with a few advantages with regard to the logistics of all the stakeholders involved, including external guests, and the multimedia of online platforms. We believe that, while this course could, theoretically, be converted to a fully online platform, some of the characteristics of face-to-face classroom settings, including the ease and rapid delivery of feedback on group activities, and the overall learning atmosphere of a classroom, can also benefit learning and teaching settings. In this sense, while this work was drafted while the pandemic remains serious, with unclear positions about the future of the classroom, we indicate that the valuable learning and advancements of PBL practices in the classroom can be adapted, and evolved, following the trends of good teaching and learning practices. 


\begin{abstract}
Author Contributions: Conceptualization, M.A.C.P. and C.E.R.R.; methodology, M.A.C.P., L.M.N.d.C.I. and C.E.R.R.; formal analysis, M.A.C.P., L.M.N.d.C.I. and C.E.R.R.; investigation, M.A.C.P., L.M.N.d.C.I. and C.E.R.R.; resources, M.A.C.P.; writing—original draft preparation, M.A.C.P., L.M.N.d.C.I. and C.E.R.R.; writing—review and editing, M.A.C.P., L.M.N.d.C.I. and C.E.R.R.; visualization, C.E.R.R.; supervision, M.A.C.P.; project administration, M.A.C.P. All authors have read and agreed to the published version of the manuscript.
\end{abstract}

Funding: This research received no external funding.

Institutional Review Board Statement: Ethical review and approval were waived for this study, due to the fact that this research involved no greater than minimal risk to participants.

Informed Consent Statement: Informed consent was obtained from all subjects involved in the study.

Data Availability Statement: Not applicable.

Conflicts of Interest: The authors declare no conflict of interest.

\title{
References
}

1. Al-Zahrani, A.M. From passive to active: The impact of the flipped classroom through social learning platforms on higher education students' creative thinking. Br. J. Educ. Technol. 2015, 46, 1133-1148. [CrossRef]

2. Hartikainen, S.; Rintala, H.; Pylväs, L.; Nokelainen, P. The Concept of Active Learning and the Measurement of Learning Outcomes: A Review of Research in Engineering Higher Education. Educ. Sci. 2019, 9, 276. [CrossRef]

3. Pereira, M.A.C.; Barreto, M.A.M.; Pazeti, M.J.P. Application of Project-Based Learning in the First Year of an Industrial Engineering Program: Lessons Learned and Challenges. Available online: https://www.scielo.br/j/prod/a/VYwQDcV3SpZZLM7ZHRh5 GhL/?lang=en (accessed on 4 November 2021).

4. Abbott, D.; Chipika, S.; Wilson, G. The potential of problem-based learning to enhance engineering education in African universities. J. Int. Dev. 2019, 32, 44-61. [CrossRef]

5. Fernandes, S.; Mesquita, D.; Flores, M.A.; Lima, R.M. Engaging students in learning: Findings from a study of project-led education. Eur. J. Eng. Edu. 2014, 1, 55-67.

6. Zhou, C.; Shi, J. A cross-cultural perspective to creativity in engineering education in problem-based learning (PBL) between Denmark and China. Int. J. Eng. Educ. 2015, 1, 12-22.

7. Voss, C.; Tsikriktsis, N.; Frohlich, M. Case research in operations management. Int. J. Oper. Prod. Manag. 2002, 22, 195-219. [CrossRef]

8. Denzin, N.K. Triangulation 2.0. J. Mix. Methods Res. 2012, 6, 80-88. [CrossRef]

9. Flick, U. Qualitative Research in Sociology in Germany and the US-State of the Art, Differences and Developments. Available online: https:/ / www.qualitative-research.net/index.php/fqs/article/view/17 (accessed on 12 October 2021).

10. Mehta, S.; Sellnow, T. Measurement and analysis of student engagement in university classes where varying levels of PBL methods of instruction are in use. High. Educ. Res. Dev. 2005, 24, 5-20. [CrossRef]

11. Hall, A.; Miro, D. A Study of Student Engagement in Project-Based Learning Across Multiple Approaches to STEM Education Programs. Sch. Sci. Math. 2016, 116, 310-319. [CrossRef]

12. Li, H.; Öchsner, A.; Hall, W. Application of experiential learning to improve student engagement and experience in a mechanical engineering course. Eur. J. Eng. Educ. 2017, 44, 283-293. [CrossRef]

13. Gomes, F.S.; Rosa, M.L.T.M.; Rodrigues, M.D.A.; Da Silva, T.A.G. Canal no youtube em busca da promoção da educação de qualidade no brasil. In Proceedings of the Congresso Brasileiro de Educação em Engenharia (COBENGE), online, 1-3 December 2020. [CrossRef]

14. Mateus, A.L.D.; Cintra, C.F.; Provasi, E.L.; Gentil, P.H.V.; Júnior, W.D.D.O.; Dias, W.V. Estratégias Educacionais e Suas Diferentes Aplicações Como Complemento na Promoção de uma Educação Equitativa. 2020. Available online: http://abenge.org.br/sis_

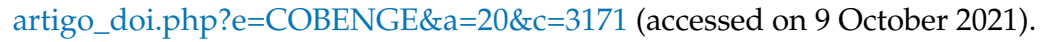

15. Nikita, V.M.; Elena, S.S.; Ulyana, M.S. Motivation System of Students and Teaching Staff of Higher Educational Institutions for Research Work Accomplishment. Procedia Soc. Behav. Sci. 2015, 166, 265-269. [CrossRef]

16. Serhan, D. Transitioning from Face-to-Face to Remote Learning: Students' Attitudes and Perceptions of using Zoom during COVID-19 Pandemic. Int. J. Technol. Educ. Sci. 2020, 4, 335-342. [CrossRef]

17. Gelles, L.A.; Lord, S.M.; Hoople, G.D.; Chen, D.A.; Mejia, J.A. Compassionate Flexibility and Self-Discipline: Student Adaptation to Emergency Remote Teaching in an Integrated Engineering Energy Course during COVID-19. Educ. Sci. 2020, 11, 304. [CrossRef]

18. Bao, W. COVID-19 and online teaching in higher education: A case study of Peking University. Hum. Behav. Emerg. Technol. 2020, 2, 113-115. [CrossRef]

19. Affouneh, S.; Khlaif, Z.; Burgos, D.; Salha, S. Virtualization of Higher Education during COVID-19: A Successful Case Study in Palestine. Sustainability 2021, 13, 6583. [CrossRef] 
20. Khlaif, Z.N.; Salha, S.; Kouraichi, B. Emergency remote learning during COVID-19 crisis: Students' engagement. Educ. Inf. Technol. 2021, 26, 7033-7055. [CrossRef]

21. Rapanta, C.; Botturi, L.; Goodyear, P.; Guàrdia, L.; Koole, M. Online University Teaching During and After the Covid-19 Crisis: Refocusing Teacher Presence and Learning Activity. Postdigital Sci. Educ. 2020, 2, 923-945. [CrossRef] 